\title{
RIGHT SUPERIOR POLAR ARTERY ARISING FROM AORTA.
}

Sreekanth Tallapaneni, Simmi Soni, Bhimasani Harika, Devarakonda Manisha, Akhilesh Raj.

1. Associate Professor. Department of Anatomy, Shadan Institute of Medical Sciences Teaching Hospital \& Research Centre.

2. Associate Professor. Department of Anatomy, Dr. V. R. K. Womens's Medical College Teaching Hospital \& Research Centre.

3. Medical Student, Department of Anatomy, Shadan Institute of Medical Sciences Teaching Hospital \& Research Centre.

4. Medical Student, Department of Anatomy, Shadan Institute of Medical Sciences Teaching Hospital \& Research Centre.

5. House Surgeon, Department of Anatomy, Shadan Institute of Medical Sciences Teaching Hospital \& Research Centre.

\section{CORRESPONDING AUTHOR:}

Sreekanth Tallapaneni, 237/2RT, 10-3-799, Vijayanagar Colony, Hyderabad, Andhra Pradesh.

E-mail: anatomysreekanth18@yahoo.com

ABSTRACT: The renal vasculature was always a subject of variations both in the number and pattern of portal of entry into kidney and Perihilar placement of the artery, vein and pelvis. Good anatomical insight is an essential prerequisite besides the surgical expertise. The cadaveric dissection at Shadan Institute of Medical Sciences, Teaching Hospital and Research Centre, revealed superior / upper polar artery arising from the lateral aspect of the aorta just proximal to the origin of Main Renal Artery (MRA). The main renal artery and the accessory renal artery had almost a common point of origin. The peri-hilar segmentation of the main renal artery was a fork like pattern. One of the segmental arteries was long and had its portal of entry into the kidney by perforating the capsule of the anterior substance of the kidney. The remaining segmental branches had their portal of entry through the hilum. The lower two segmental branches were placed anterior to the main renal vein causing altered hilar anatomy. A thorough knowledge of the frequently to the rarely occurring wide range of variations of renal vasculature has significance in exploration and treatment of renal trauma, renal transplantation, renal artery embolization, surgery for abdominal aortic aneurysm and conservative or radical renal surgery. Such a rare variation including the combination of extra renal peri-hilar segmentation of MRA with superior polar artery is worthy of concern to the urologists harvesting kidneys from the live donors for performing transplantation procedures, partial nephrectomies for the hilar tumors and for Radiologists during interpretation of the angiograms.

KEY WORDS: (Upper / Superior polar artery) (Peri-hilar segmentation) (Portal of entry) (Altered hilar anatomy).

INTRODUCTION: Each kidney is supplied by a renal artery which arises from abdominal aorta below the origin of superior mesenteric artery on each side. Right renal artery is longer than the left renal artery, because abdominal aorta lies on the left side of vertebral column. The renal artery divides into anterior \& posterior trunks. Anterior trunk passes in front of the renal pelvis and usually subdivides into four segmental arteries apical, upper and anterior, middle and 
anterior, inferior. Posterior trunk passes behind the renal pelvis and is continued as the posterior segmental artery [1]. Occasionally an accessory renal artery arising from the aorta or an aberrant artery supplies the superior or the upper pole of the kidney without passing through the hilum. An accessory artery is the precocious origin of a segmental artery. The presence of an accessory / aberrant renal artery at the lower pole is in fact a segmental vessel that is persisted foetal vessel with an abnormal origin [2]. True aberrant vessels are rare except in patients with renal ectopia (with or without fusion) and in individuals with a horse shoe kidney. True aberrant renal arteries are those which may arise from common iliac, external iliac, internal iliac, middle sacral, testicular, inferior phrenic or superior mesenteric arteries. Near the hilum of the kidney, each renal artery divides into anterior and posterior branches, which in turn divides into number of segmental arteries supplying the different renal segments. The presence of unusual branching patterns of the renal arteries is not uncommon. In $70 \%$ of cases there is a single renal artery supplying each kidney [3]. Anatomical variations and congenital anomalies of the renal veins have been well described by many authors. Numerous reports have appeared in the literature describing variations in renal vascular anatomy. Knowledge of the variations of renal vascular anatomy has importance in exploration and treatment of renal trauma, renal transplantation, renovascular hypertension, renal artery embolization, angioplasty or vascular reconstruction for congenital and acquired lesions, surgery for abdominal aortic aneurysm and conservative or radical renal surgery [4].

EMBRYOLOGY: The embryological explanation of these variations has been presented and discussed by Keibel F and Mall FP [5]. In an $18 \mathrm{~mm}$ fetus, the developing mesonephros, metanephros, suprarenal glands and gonads are supplied by nine pairs of lateral mesonephric arteries arising from the dorsal aorta. Felix divided these pairs of arteries into three groups as follows: the $1^{\text {st }}$ and $2^{\text {nd }}$ arteries as the cranial group, the $3^{\text {rd }}$ to $5^{\text {th }}$ arteries as the middle group and $6^{\text {th }}$ to $9^{\text {th }}$ arteries as the caudal group. The middle group gives rise to renal arteries. Persistence of more than one renal artery of the middle group results as multiple renal arteries [5]. Thus, the duplicated renal arteries in our study are a result of two persisting lateral mesonephric arteries from the middle group. Accessory renal arteries are found frequently on the left side and their occurrence is as high as $30-35 \%$ of cases. These arteries usually enter the upper or lower poles of the kidney [6].

MATERIALS AND METHODS: A formalin - fixed elderly male cadaver along with Routine instruments like a pair of gloves, Scalpel, Blade, Surgical forceps, Anatomical Forceps, Dissector, Metallic Scale with Calibrations were used. Kidneys are a pair of excretory organs lying over the posterior abdominal wall on either side of vertebral column retro-peritoneally. The anterior abdominal wall was dissected layer by layer. The visceral organs like liver, stomach and intestines were all studied in Situ and dissected out. The duodenum, pancreas and spleen were all dissected away from the abdominal cavity and the peritoneum was striped to visualize the kidneys. The right kidney was seen in the normal anatomical position. After sectioning the Left Main Renal Vein (LMRV) and manipulating (forward bending of) the Inferior Vena Cava (IVC) the peri-hilar segmentation of the Right Main Renal Artery (RMRA) and the accessory renal artery supplying the upper pole was seen.

OBSERVATION: The Main Renal Artery (MRA) was seen arising from the lateral aspect of the aorta extending laterally towards the hilum of the right kidney. The MRA showed early peri- 
hilar segmentation into five branches in fork like pattern. Just proximal to the origin of the main renal artery the accessory renal artery arose which coursed horizontally towards the upper pole of the right kidney and supplied it by piercing the medial border. The main renal artery and the accessory renal artery almost had a common point of origin. All the five segmental arteries were anterior branches and extended laterally towards the hilum except the first long segmental artery. All of them were of approximately same diameter. The first and the longest segmental artery was extending over the anterior surface of the kidney and had its portal of entry by piercing the capsule of the anterior substance of the kidney almost $3 \mathrm{~cm}$ lateral to the medial border. The portal of entry of other segmental arteries was through the hilum. The lower two segmental arteries were lying anterior to the Main Renal Vein (MRV) causing alteration in the hilar anatomy. None of the segmental arteries had subsidiary branches. The ureter was the most posteriorly placed structure in the hilum.

DISCUSSION: Merklin and Michele (1958) analyzed reports from almost 11000 kidneys and reported that vascular variation with one hilar artery and one upper polar aortic artery to be $6.2 \%$ rarely the upper segment is supplied from a branch totally separate from the main renal artery (7). In the present case the accessory renal artery was proximal to the Main Renal Artery (MRA) in its origin but almost had a common point of origin.

Ronald-Eisendrath (1920) after examination of 1237 kidneys by various investigators revealed that the occurrence of upper polars from aorta in 68, or nearly $0.5 \%$, of 1237 kidneys (8). In the present case the upper polar artery arose from the antero lateral aspect of the aorta almost abutting the main renal artery.

Ozanko after analyzing 855 angiograms concluded that the occurrence of the multiple arteries was $24 \%$ out of which $16 \%$ were occurring on the right side and $13 \%$ on the left side (9). In the present case the accessory artery was arising to supply the right kidney at its upper pole.

Mohammadali M. Shoji studied arteriograms of 81 Kidneys and identified the peri-hilar branching pattern and morphology of main renal artery to be a fork pattern (with Common Branching point) in $92.6 \%$ and a ladder pattern in $7.4 \%$ in the present case the MRA showed fork pattern type of perihilar branching into 5 segmental ( 4 anterior and 1 posterior) branches (10). In the present case the MRA showed a fork like pattern of early peri-hilar branching. There were five segmental branches and interestingly all of them were anterior. The first and the longest branch had its portal of entry through anterior substance of the kidney midway between the upper pole and upper part of the hilum. The remaining four branches entered through hilum and the lower two segmental branches were anterior to the main renal vein.

Kyle. J, Performed precise extraparenchymal renal hilar dissection on 73 fixed cadaveric kidneys and reported the vascular anatomy to be pre-segmental and segmental branches of the MRA. These consisted of Zero, One, or Two pre-segmental arteries (external main renal artery branches that split into two or more segmental arteries) in $49.3 \%, 31.5 \%$ and $19.2 \%$ of the kidneys respectively. From a posterior approach, the posterior segmental artery was accessible to isolated clamping in $81.8 \%$ of the kidneys. The total accessibility rate for inferior segmental artery was $88.5 \%$ from anterior and $6.7 \%$ from a posterior surgical approach respectively. Segmental artery clamping is anatomically feasible and minimizes the number of nephrons exposed to potential ischemic injury (11). In the present case it was early peri-hilar segmentation and all the segmental branches were anterior only. The posterior segmental branch was not seen. 
Bilateral prehilar multiple branching of the renal arteries soon after their origin with the superior polar artery giving rise to the inferior supra renal artery was reported by RAO M (12). In the present case the upper polar artery did not give any inferior supra renal artery it only supplied the upper pole of the right kidney.

Digital subtract angiography is the gold standard for the detailed anatomical assessment of the renal vasculature for living donors. However Multi Detector - row Computerized Tomography (MDCT) is less invasive than digital subtract angiography and more accurate in the evaluation of the renal arterial anatomy such as the number, origin of the renal arteries, presence of the segmental branches and intrinsic renal artery disease and renal venous anatomy such as presence of accessory veins, retro aortic and circum aortic veins by using venous phase axial images in the living donors. According to Tombul ST the Pre-operative evaluation of the hilar vessel anatomy with 3-D computerized tomography is of great help to those patients undergoing Laparoscopic partial nephrectomy for hilar tumors as they come in direct contact either with the renal vein or artery or both (13). Amanjot S. Sethi, opined that the use of a Doppler ultrasound probe during vascular dissection in Laparoscopic renal surgery is a fast, efficient and simple means of identifying the renal hilum. The meantime for the identification of all the renal vessels was 34.9 seconds, and the mean time to surgically isolate all the hilar vessels was 44.6 minutes without any technical difficulties (14). The present variation is an ideal case for pre-operative evaluation of the hilar vessel anatomy as there was an alteration in the hilar anatomy due to the varied placement of the renal vasculature. The lower two segmental branches were placed anterior to the renal vein.

CONCLUSION: The vasculature develops through haemo-dynamically induced modeling and remodeling of numerous primitive vascular precursors. It has been shown that some of these anomalies have a genetic basis while others have an abnormal embryonic or environmental factors contributing to the pathogenesis. Were the health care personnel to remain unaware of the body's prenatal progress towards maturity they would be baffled by every example of departure from the archetypal pattern or supposedly constant anatomic form. In my view "VARIANT ANATOMY ILLUMINATES EMBRYOLOGY". It has been repeatedly stated in the literature that the modern text book descriptions are accurate or hold in only about $50-70 \%$ of individuals. In the era of modern vision with latest and non-invasive investigations such as ultra-sonography, computerized Axial Tomography, Angiography, Arterio-graphy and Various other specific imaging modalities are in use to detect all the different types of vascular anatomy which has great importance in exploration and treatment of renal trauma, renal transplantation, renal artery embolization, surgery for abdominal aortic aneurysm and conservative or radical renal surgery. Such a rare variation including the combination of extra renal peri-hilar segmentation of MRA with superior polar artery is of worth concern to the urologists harvesting kidneys from the live donors for performing transplantation procedures, partial nephrectomies for the hilar tumors and for Radiologists during interpretation of the angiograms.

ACKNOWLEDGEMENTS: This publication is dedicated to our Chairman Sir Dr. VIZARATH RASOOL KHAN Saab with utmost reverence \& motherly affectionate SHADAN MADAM for all their encouragement, motivation \& kindness extended to us.

\section{REFERENCES:}


1. William PL, Bannister LH, Berry MM, Collins P, Dysen M, Dusek JE et al. cardiovascular system. Gray's Anatomy, The anatomical basis of Medicine and Surgery, 38 ${ }^{\text {th }}$ edition, Ch - 10 Pg - 1547.

2. R.M.H. Mcminn, Last's Anatomy Regional and Applied, $8^{\text {th }}$ Edition, $\mathrm{Ch}-5, \mathrm{Pg}-370-372$.

3. Standring S. Gray's Anatomy. The Anatomical Basis of Clinical Practice. 39th Ed. London, Elseiver Churchill Livingstone Publishers. 2005; 1274-1275.

4. Nathan H, Glezer I. Right and left accessory renal arteries arising from a common trunk associated with unrotated kidneys. J Urol. 1984; 132; 7 - 9.

5. Keibel F Mall FP (eds), Manual of human embryology, Vol. 2, J.B. Lippincott, Philadelphia, 1912, 820-825.

6. Singh G, NG YK, Bay BH, Bilateral accessory renal arteries associated with some anomalies of the ovarian arteries: a case study, Clin Anat, 1998, 11(6): 417-420.

7. Merklin R.J \& Michele, N.A (1958) The variant renal and supra renal blood supply. J. Internat. Coll. Surgeons. 29:41.

8. Ronald A. Bergman, PhD, Adel K. Afifi, MD, MS, Ryosuke Miyauchi, MD, Inferior Renal Polar Arteries. Illustrated Encyclopedia of Human Anatomic Variation: Opus II: Cardiovascular System: Arteries: Abdomen: Variations in Branches of Celiac Trunk:

9. Ozkhan U, Oguzkurt L, Tercan F, Kizilklic o, Kocz, Koca N Renal artery origins and variations: angiographic evaluation of 855 consecutive patients. Diagn inerv radiol; 2008 12: 183 - 188.

10. Mohammadali M. Shoja, R. Shane Tubbs, Abolhassan Shakeri, Marios Loukas, Mohammad R. Ardalan, Hamid T. Khosroshahi and W. Jerry Oakes. Surgical and Radiolgogic Anatomy, Volume: 30, Number 5, July, 2008, Pg: 375-382.

11. Kyle J, Weld, Sam B. Bhayani. Jay Belani, Carroline D. Ames, Greg Hruby and Jaime Landman Extra renal Vascular Anatomy of Kidney. Assessment of Variations and their Relevance to Partial Nephrectomy from the Division of Urology, Washington University School of Medicine. St Louis Missouri. Urology 66: 985-989, 2005.

12. Rao M, Bhat SM, Venkataramana V, Deepthinath R, Bolla SR. Bilateral prehilar multiple branching of renal arteries: A case report and literature review. Kathmandu University Medical journal (2006), Vol. 4, No. 3, issue 15, 345 - 348.

13. Tombul ST; Aki FT; Gunay M; Inci K; Hazirolan T; Karcaaltincaba M; Erkan I; Bakkaloglu A; Yasavul V; Preoperative evaluation of hilar vessel anatomy with 3-D computerized tomography in living kidney donors. Tombul ST - Transplant Proc - 0.1 -Jan-2008; 40 (1): $47-9$.

14. Amanjot S. Sethi, M.D., Stanton M. Regan, MD, and Chandru P. Sundaram, M.D The use of A Doppler Ultrasound Probe During Vascular Dissection in Laproscopic Renal Surgery. Journal of Endourology Volume; 23 Number 9; September 2009. 


\section{CASE REPORT}

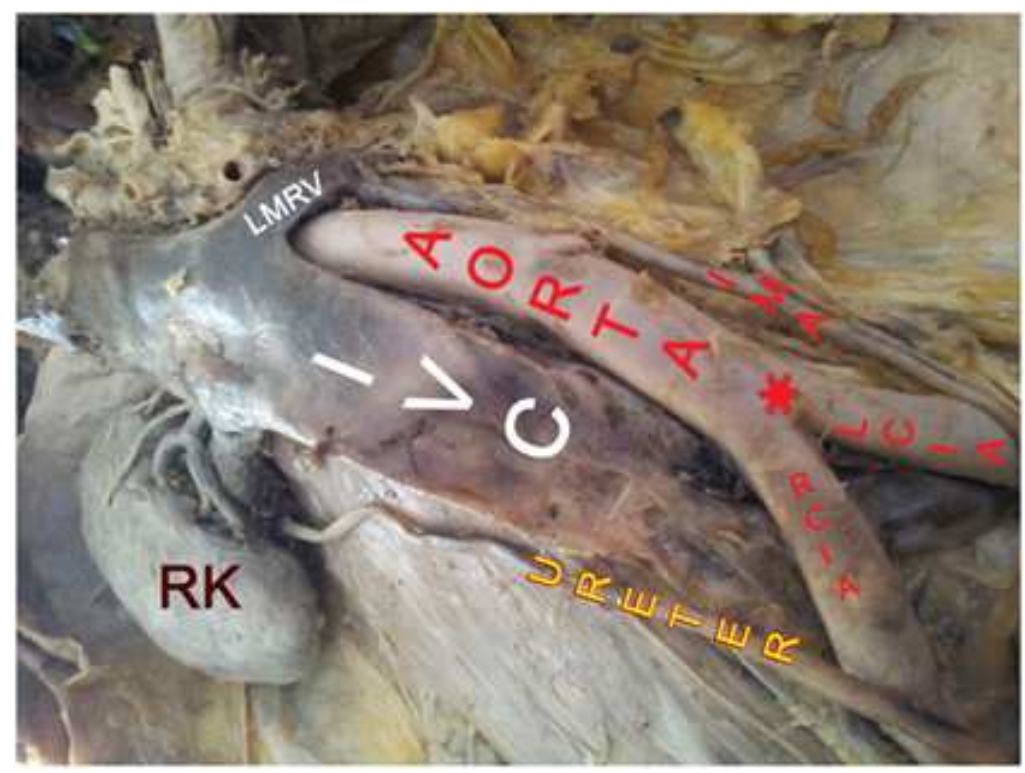

FIGURE : 1 DISSECTED RIGHT KIDNEY- IN SITU

IVC - INFERIOR VENA CAVA, RK - RIGHT KIDNEY, LMRV - LEFT MAIN RENAL VEIN, LCIA - LEFT COMMON ILIAC ARTERY, RCIA - RIGHT COMMON ILIAC ARTERY, IMA INFERIOR MESENTERIC ARTERY.

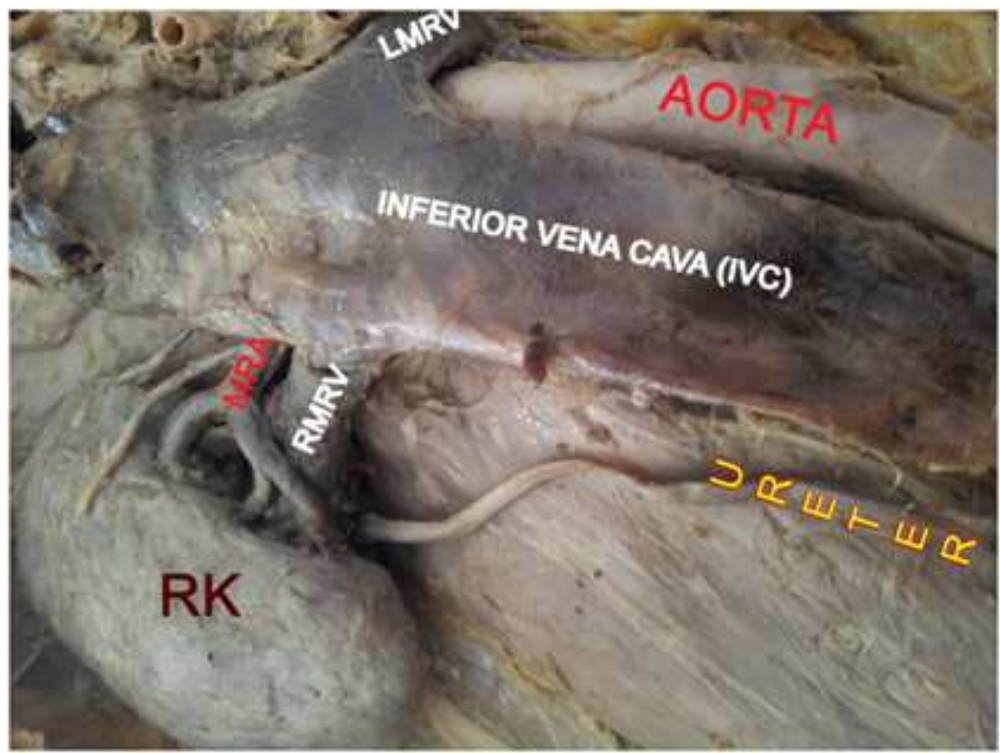

FIGURE: 2 SUPERIOR ANTERIOR DISSECTED RIGHT KIDNEY- IN SITU - ZOOM IN VIEW

MRA - MAIN RENAL ARTERY, RMRV - RIGHT MAIN RENAL VEIN, IVC - INFERIOR VENA CAVA, RK - RIGHT KIDNEY, LMRV - LEFT MAIN RENAL VEIN. PERI-HILAR SEGMENATION OF THE MAIN RENAL ARTERY IS SEEN. THE PORTAL OF ENTRY OF ONE OF THE SEGMENTAL BRANCHES IS SEEN, BY PIERCING THE ANTERIOR SUBSTANCE OF THE KIDNEY 3 CM AWAY FROM THE MEDIAL BORDER OF THE HILAR OF THE KIDNEY. 


\section{CASE REPORT}

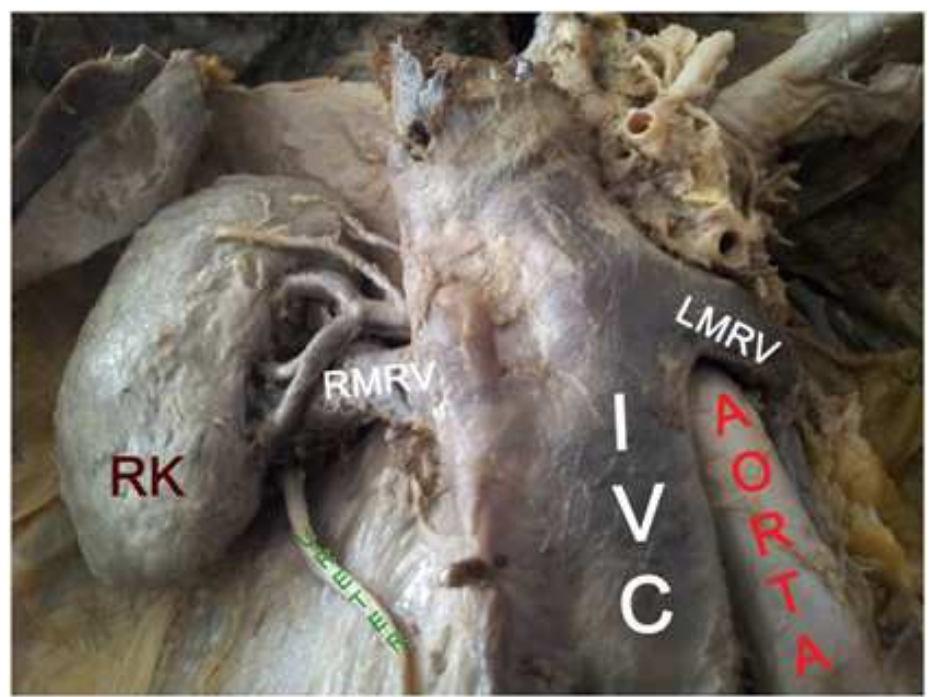

FIGURE: 3 ANTERIOR VIEW OF DISSECTED RIGHT KIDNEY- IN SITU

IVC - INFERIOR VENA CAVA, RK - RIGHT KIDNEY, LMRV - LEFT MAIN RENAL VEIN, RMRV - RIGHT MAIN RENAL VEIN

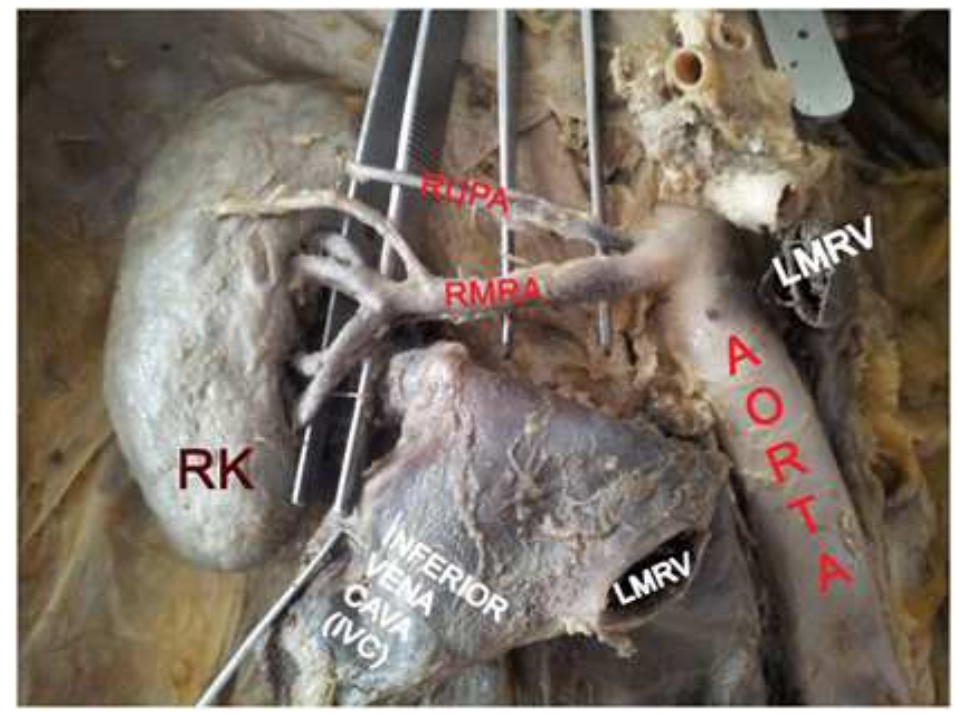

FIGURE: 4 RIGHT ANTERO - LATERAL VIEW OF DISSECTED RIGHT KIDNEY- IN SITU

THE LEFT MAIN RENAL VEIN WAS CUT AND THE IVC WAS MANIPULATED FORWARDS TO VISUALIZE THE RIGHT MAIN RENAL ARTERY (RMRA) \& RIGHT UPPER POLAR ARTERY (RUPA).

THE CUT ENDS OF LEFT MAIN RENAL VEIN (LMRV) ARE SEEN . THE MAIN RENAL ARTERY (RMRA) AND ITS PERI-HILAR SEGMENTATION CAN BE SEEN.

THE UPPER POLAR AORTIC ARTERY IS SEEN SPROUGHTING FROM THE LATERAL ASPECT OF THE AORTA. PROXIMAL AND ABUTTING THE MAIN RENAL ARTERY. IVC - INFERIOR VENA CAVA, RK - RIGHT KIDNEY, LMRV - LEFT MAIN RENAL VEIN, RMRV - RIGHT MAIN RENAL VEIN 


\section{CASE REPORT}

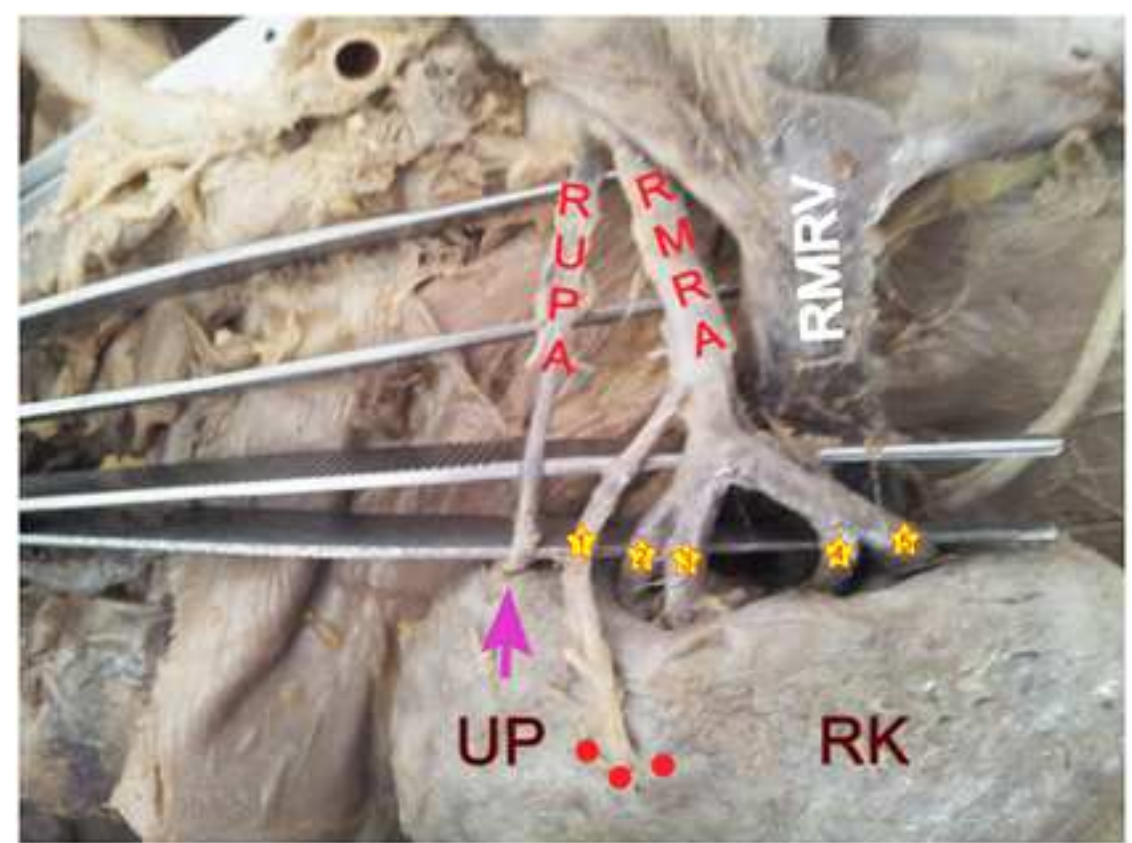

FIGURE: 5 SUPERIO LATERAL VIEW OF DISSECTED RIGHT KIDNEY- IN SITU ZOOM IN VIEW

THE MAIN RENAL ARTERY WITH ALL ITS SEGMENTAL BRANCHES IS SEEN. (SEGMENTAL BRANCHES ARE MARKED BY STARS AND NUMBERED FROM 1TO 5 WITHIN YELLOW STARS).

THE FIRST AND THE LONGEST SEGMENTAL ARTERY IS SEEN ENTERING THE KIDNEY THROUGH THE ANTERIOR SUBSTANCE 3 CM LATERAL TO THE HILUM. ITS PORTAL OF ENTRY IS MARKED BY 3 RED DOTS ON THE ANTERIOR SURFACE OF THE KIDNEY.

THE UPPER POLAR ARTERY IS SEEN ENTERING THE KIDNEY AT THE UPPER POLE MARKED BY PINK ARROW ALONG THE MEDIAL BORDER.

UP - UPPER POLE, RK - RIGHT KIDNEY, RUPA - RIGHT UPPER POLAR ARTERY, RMRA RIGHT MAIN RENAL ARTERY, RMRV - RIGHT MAIN RENAL VEIN. 